Revista de Ciencias Sociales - Número 63 (2013) - Páginas 87-111

América y su articulación jurídico-política en las Cortes Extraordinarias de Cádiz

\title{
AMÉRICA Y SU ARTICULACIÓN JURÍDICO-POLÍTICA EN LAS CORTES EXTRAORDINARIAS DE CÁDIZ
}

\author{
AMERICA AND ITS JURIDICAL-POLITICS \\ INTEGRATION IN EXTRAORDINARY \\ COURTS OF CADIZ
}

LUIS MIGUEL GARCÍA LOZANO*

Programa de Doctorado Universidad de Bolonia luisgarcia350@hotmail.com

\section{Resumen}

La situación de desgobierno a la que sucumbió el Imperio así como las insurrecciones derivadas de los abusos en las Provincias, exigían una reglamentación que otorgase un marco jurídico al que atenerse y que sirviera de marco para la regulación de las instituciones que deberían hacer de conducto y canal para ejecutar las decisiones y órdenes de la Regencia y las Cortes Extraordinarias reunidas en ausencia de la corona.

\section{Palabras claves}

Colonias, Dominios de Ultramar, Provincias, América, Cortes de Cádiz, Metrópoli, Españoles.

* Abogado y colaborador con la Cátedra de Derecho Administrativo de la Universidad de Bolonia y la Scuola de Amministrazione Pubblica di Bologna. Doctorando en Historia del Derecho por la Universidad de Murcia y en Derecho Administrativo por la Universidad de Bolonia-Alma Mater Studiorum. Artículo recibido el 4 de septiembre de 2013 y aceptado el 27 de noviembre de 2013.

Revista de Ciencias Sociales - Número 63 (2013) - Universidad de Valparáíso - ISSN 0716-7725-Valparaíso, Chile 


\section{Abstract}

The situation of lawlessness of the Spanish Empire and the insurrection arising from abuses in the provinces, demanded a regulation to complete the legal framework. This regulation became in a very important regulation to the institutions, where the Politicians can see the duct and channel to execute the decisions and orders of the Regency and extraordinary courts gathered in the absence of the Crown.

\section{Keywords}

Colonies, domains of overseas provinces, America, Cortes de Cádiz, metropolis, Spanish.

"Porque la Justicia ensancha las poblaciones, como la falta della las deshaze"'.

\section{Antecedentes: la visión de américa desde España}

En la reunión de Cortes en Cádiz se puso de relieve de un modo definitivo la variación de mentalidad que acontecía en España. Las cosas aunque lentamente, van cambiando de modo radical. Poco a poco, pero sin vuelta atrás, los aires liberales se dejan notar e influyen en la forma de actuar de las Cortes. Este cambio también se observa en la mentalidad de los territorios, que ya no desean depender única y exclusivamente de la Metrópoli. Las colonias son parte integrante de la Monarquía, y como tal quieren participar de las decisiones del país, regir sus destinos y los del resto de los españoles, pero sobre todo, tomar parte de las decisiones que afectan a sus territorios, exigiendo tener una representación igual a la que pudieran tener los españoles peninsulares.

La percepción que desde la Metrópoli se tenía de las colonias era de algo lejano, y cuyas inquietudes y problemas no pasaban por ser importantes, ni mucho menos al mismo nivel que los de la Metrópoli. A veces, esta lejanía desembocaba en que los asuntos americanos para

1. ALBORNOZ, Bartolomé Frías de: Arte de los Contratos. Casa de Pedro Huete. Valencia. 1573. Pág. 14.

Facultad de Derecho y Ciencias Sociales - Universidad de Valparaíso - Chile 
los peninsulares eran algo ajeno, y la lejanía hacía que los asuntos perdieran importancia. Este criterio se mantuvo durante siglos, tal vez en parte, acusado por él propiamente, por la propia naturaleza jurídica de las colonias como dominios reales, y por otro lado, por la forma de gobierno y las demarcaciones trazadas, en las que ningún territorio tenía que ver con otro, pero a su vez eran bastas extensiones de terreno.

Esta idea continúa presente en la Cádiz del s. XIX, siguiendo la dinámica histórica y como no puede ser de otra manera, se deduce de las alocuciones que en las sesiones de las Cortes se suceden. Obviamente, los españoles peninsulares hacen ver en diversas oportunidades que los asuntos americanos no tienen la importancia tan capital que puedan tener los metropolitanos, que por ello, es la cabeza de todo el Imperio Español y desde donde se impartían las órdenes reales a ejecutar.

\section{El cambio de mentalidad. Hacia un nuevo sistema provincial en las Américas}

\subsection{América y su personalidad propia en las Cortes}

Desde el inicio de las reuniones de las Cortes en la Real Isla de León y en Cádiz, los representantes Americanos pretendían dejar ver que América era una cosa distinta de la Metrópoli, y que pese a la lejanía, Europa debía tener en cuenta que aquel territorio era muy superior en extensión al de la propia España europea. Como era de esperar, esto se trasladó a la reivindicación de una igualdad en la representación en las Cortes. Así las cosas, encontramos que en la sesión del 2 de octubre se presenta por el Presidente, un memorial «que le habian entregado varios españoles europeos establecidos en la América septentrional» ${ }^{2}$ pidiendo que se les incorporase entre los diputados de América aunque fuera como suplentes.

Otra petición que viene a dar ejemplo fue la que realizó poco después el diputado Mejía, cuando en la sesión del 7 de octubre, presentó

2. Diario de sesiones de las Cortes Generales y Extraordinarias: dieron principio el 24 de setiembre de 1810 y terminaron el 20 de setiembre de 1813. Sesión día 2 de octubre de 1810. (Imprenta de J. A. García. Madrid. 1870-1874). [= D.S.C.]Vol. I. Pág. 19.

Revista de Ciencias Sociales - Número 63 (2013) - Universidad de Valparáiso - ISSN 0716-7725-Valparáís, Chile 
una propuesta en la que pedía que se viese si convenía o no una «comisión particular de Comercio», y «que de esta comisión hayan de ser, entre otros, precisamente los dos Sres. Diputados de la ciudad y Junta de Cádiz, y dos Diputados americanos» ${ }^{3}$, habida cuenta que el mayor volumen de negocio en España, venía de América y pasaba por la Casa de Contratación gaditana. Sin embargo, se admitió la primera parte, y la segunda la retiró el propio Mejía, aunque el diputado Rodríguez Bárcenas la reprodujo en los mismos términos y en la misma sesión, no siendo aceptada. Esto viene a ser ejemplo de cómo los propios diputados americanos querían dar una posición a América igual a la que tenía la Metrópoli. Pero esto sólo son dos ejemplos de lo que cada vez, y con mayor asiduidad, se intentaría por parte de los americanos, que no era otra cosa que poner aquel territorio y el peninsular en igualdad de condiciones.

Un nuevo ejemplo a destacar lo encontramos en la sesión de 9 de enero de 1811, en la que se reivindica que se completara de una vez la representación de América en las Cortes siendo el diputado Gutiérrez de Terán quien lo defendió, argumentando que había

«oído decir que esto debía resolverse cuando se formase la Constitución, y que por ahora debiamos atender a otros medios para procurar la felicidad de América. Señor, yo creo que no sería justo que estando completa la representación de la península no lo estuviese también la de las Américas, ni sería justo privar a aquellos habitantes de tener el honor de contribuir con sus luces á la grande obra de la Constitución. Se dice que está representada la América; es cierto: también lo está la provincia de Valencia, y sin embargo, cuando $V$. M. supo que cuatro de sus individuos cayeron en manos de los franceses, mandó viniesen otros en su lugar. Y si por varios incidentes faltase toda la representación valenciana, V. M. mandaría que se nombrasen nuevos. ¿Pues qué razón hay, siendo tan fácil designar el número de los Diputados de América, para que haya en esto tanta frialdad, o sea dilación?» ${ }^{4}$. El diputado culmina todo esto añadiendo que «V. M. ha mandado al Poder ejecutivo que active la

3. D. S. C. Sesión día 7 de octubre de 1810. Pág. 29.

Facultad de Derecho y Ciencias Sociales - Universidad de Valparaíso - Chile 
traslación de todos los Diputados; esto mismo debe hacer con respecto á América».

Tras su alocución tomó la palabra el diputado Argüelles, quien se vio en la necesidad de darle la razón al anterior diputado.

\subsection{La publicación del Decreto de instalación de Cortes}

Todas estas reivindicaciones tuvieron un antecedente que fue el modo de hacer público a todos los territorios del Estado el Decreto de Instalación de las Cortes. Este asunto tuvo desde el primer día un importante protagonismo, pues el interés de las Cortes era hacerlo público en todos los territorios de la Monarquía a la misma vez, pero evidentemente, ello no siempre era posible. Esta cuestión hizo surgir una constante discusión sobre los modos de publicitar el Decreto de Instalación de las Cortes, que en un principio no conciliaba a todos y obligaba a postergar el tema de una a otra sesión como ocurrió en la sesión del 24 de septiembre de $1810^{5}$. El tema volvió a ser objeto de debate en la sesión siguiente ${ }^{6}$, en cuyo punto $\mathrm{V}$ se recordaba que los Diputados por América habían solicitado el día anterior que

«no debía remitirse este decreto a los dominios ultramarinos sin que fuere acompañado de varias declaraciones a favor de aquellos súbditos».

Esto determinó que una comisión al efecto nombrada y compuesta por diputados de aquellos territorios ${ }^{7}$ se reuniera para elevar

4. D. S. C. Sesión día 9 de enero de 1811. Págs. 328 y ss. Esta intervención tuvo como consecuencia el Decreto 31 de las Cortes que después se comentará. Vid. nota al pie número 36.

5. D. S. C. Sesión día 24 de septiembre de 1810. Pág. 4.

6. D. S. C. Sesión día 25 de septiembre de 1810. Pág. 5.

7. Dicha comisión se componía de los Diputados Mexías, Lisperguer, Leyva, Inca, Couto, Palacios, Ramón Power, Llano, Toledo y el Marqués de San Felipe. A este respecto: D. S. C. Sesión día 25 de septiembre de 1810.

Revista de Ciencias Sociales - Número 63 (2013) - Universidad de Valparáíso - ISSN 0716-7725-Valparáiso, Chile 
un dictamen sobre la forma en que «convendría publicar en América el decreto de instalación del día anterior».

\subsubsection{Las reivindicaciones americanas}

La falta de acuerdo a la hora de la búsqueda de solución al problema planteado obligaba a posponer su debate para la sesión siguiente. El mismo día 25 de septiembre pero en sesión nocturna, su debate ocupó gran parte de la misma. Las visiones fueron variadas en los aspectos y reclamaban que en efecto, además del decreto, se enviaran declaraciones a los dominios ultramarinos sobre su situación. Parte de la sala manifestó la necesidad de indicar en escritos anexos, «a la América de su igualdad de derechos con los españoles europeos, de la extensión de su representación nacional como parte integrante de la Monarquía», considerando esto algo principal, pues sería absurdo enviar a los compatriotas un decreto en el que se dice cuál es el nuevo régimen de gobierno, pero para nada se menciona la situación jurídica en la que quedan.

La cuestión no era en nada baladí, pues suponía una importante reivindicación de derechos, en la que se hace ver que el pueblo americano, ya no tenía gana alguna de ser una simple colonia sin voz y cuyo único derecho era contribuir a las arcas de la Metrópoli.

A su vez, y como contrapartida, era necesario hacer hincapié en «la amnistía, o por mejor decir, olvido que convendría conceder a todos los extravíos ocurridos en las desavenencias de algunos países de América», destacando así la necesidad de la promulgación de una amnistía general a todas las trifulcas que fueron surgiendo a partir de la ausencia del rey FERNANDo VII y de su padre, y su consiguiente vacío de poder, teniendo en cuenta la situación que se produjo, al haber sido descabezada una monarquía absoluta. La cuestión, no en vano, siguió siendo tratada y se solicitó que debido a su trascendencia se hiciese en secreto en esas Cortes $^{9}$, hecho que no cayó en gracia y en consecuencia acabó desestimado.

8. D. S. C. Sesión día 25 de septiembre de 1810, por la noche. Pág. 6.

9. Uno de los diputados de América, el Sr. Mejía realizó dicha propuesta.

Facultad de Derecho y Ciencias Sociales - Universidad de Valparaíso - Chile 
Del mismo modo, otros diputados por América volvieron a recalcar la necesidad de hacer expresas estas declaraciones, calificando esta medida de justa y conveniente. Pero parte de los diputados europeos, no sólo no lo veían claro, sino que lo veían «intespestivo (sic)» en ese momento por ser materia que requería «mucho pulso, exámen ${ }^{10}$ (sic) y antecedentes de que aún se carecía» ${ }^{11}$. Sin embargo, esta opinión no era unánime entre los europeos, exponiendo otros que

«era urgentísimo no detener un momento más la declaración de los decretos de ayer y de hoy, pues siendo conocidos de todo el público de Cádiz y la Isla por la publicidad de las sesiones, podría llegar la noticia a las provincias por cartas particulares antes que por el Gobierno» ${ }^{12}$.

Este comentario es de gran importancia, pues marca tres hechos, en primer lugar el cambio de denominación que algunos europeos le dan a América, pasando de dominios ultramarinos a provincias, categoría igual que se da a las regiones de la España peninsular.

Debe añadirse como segundo hecho a recalcar, que la circunstancia de conocer los territorios americanos el contenido de los decretos de instalación antes por noticias particulares, que por decretos o comunicaciones oficiales, podría suponer un hecho de importante magnitud que desembocaría en la desacreditación de las nuevas instituciones que no sabrían encauzar esta situación, y por último, la poca capacidad de actuación de las nuevas Cortes al no poder, no ya ejecutar sus propios decretos, sino hacerlos públicos en condiciones. La cuestión se suscitó con tal fuerza, que dos días después se decretaba el

10. El Legislador español, desde antiguo entendía que todas las medidas que tenían cierta trascendencia debían ser reflexionadas y no actuar bajo la premura. Sobre este particular ver: García Lozano, Luis Miguel: "Artifex Legis en el Liber Iudiciorum. Una antigua teoría con total vigencia”. En: Estudios de Derecho y Ciencia Política. Universidad de Salamanca, Salamanca, en prensa.

11. D. S. C. Sesión día 25 de septiembre de 1810, por la noche. Pág. 6.

12. D. S. C. Sesión día 25 de septiembre de 1810, por la noche. Pág. 6.

Revista de Ciencias Sociales - Número 63 (2013) - Universidad de Valparáíso - ISSN 0716-7725-Valparaíso, Chile 
cierre del puerto de Cádiz «con el objeto de que no se enviasen á América noticias particulares de la instalacion de las mismas (las Cortes) antes de que partiesen de oficio» ${ }^{13}$.

Pese a ello, nadie negaba que todos los territorios eran uno y que todos los dominios eran España y, por tanto, dichas declaraciones cabían, pero sería conveniente hacerlas «en su tiempo». La cuestión, pues, pasaba por algo tan sencillo, pero a su vez tan complicado como era reformular lo que se entendía como América, haciendo esto extensivo a los demás territorios españoles. Sólo así conseguirían que «aquellas provincias de Ultramar hayan reconocido la autoridad legítima» ${ }^{14}$ de las Cortes.

Dos propuestas se hicieron sobre el modo de solucionar esta cuestión, una realizada por los Diputados de América y otra por el diputado Oliveros ${ }^{15}$, siendo esta la que finalmente se tomó en consideración; pero que el propio autor estimaba necesario se completase con los antecedentes y noticias que indicaba en la misma, aprobándose que se pidiesen ${ }^{16}$.

Poco a poco, las peticiones de los diputados de América tomaban cuerpo, y se veían reflejadas en la vida de las Cortes. Así mismo, la influencia de América en las mismas iba en aumento habida cuenta su gran extensión ${ }^{17}$. La cuestión, sin embargo, y teniendo en cuenta los grandes debates que estaba suponiendo, obligó a los diputados a llegar a un entendimiento necesario para salir de un túnel que había obligado, incluso a cerrar el único puerto hábil de la España no ocupada.

Los americanos presentaron una nueva moción, que renovaba la del 24 de septiembre anterior, y se redujo en sus puntos iniciales a

13. D. S. C. Sesión día 27 de septiembre de 1810. Pág. 11.

14. D. S. C. Sesión día 1 de octubre de 1810. Pág. 18.

15. Nos referimos al diputado por Extremadura D. Antonio Oliveros, canónigo de la Colegiata de San Isidro de Madrid.

16. D. S. C. Sesión día 1 de octubre de 1810. Pág. 18.

17. Se presentó un memorial de europeos establecidos en América reclamando entre otras cosas que se les nombrase suplentes por América Septentrional.

Facultad de Derecho y Ciencias Sociales - Universidad de Valparaíso - Chile 
dos, a que las Cortes sancionasen expresamente que los dominios de Ultramar hacen parte integrante de la Monarquía Española y que no se procediese por el Gobierno a

«usar de rigor contra los pueblos de América, donde se han manifestado turbulencias o disgustos; pero que las cortes se informen de lo que el Gobierno sepa en este punto y de las medidas que haya tomado» ${ }^{18}$.

Este hecho supondría la aprobación de una amnistía general a los tumultos surgidos durante el vacío de poder en la Monarquía.

Sin embargo, y pese al cambio de la moción, tampoco hubo acuerdo y tras un largo debate, se postergó para el día siguiente, al haber más puntos que tratar en el orden del día. Pese a lo acordado no fue así y tardó mucho más en volver a tratarse. Finalmente, esta propuesta tomó cuerpo y dio como resultado el Decreto $\mathrm{V}$ por el que se otorgaba la «igualdad de derechos entre los españoles europeos y ultramarinos: olvido de lo ocurrido en las provincias de América que reconozcan la autoridad de las Cortes $^{19}{ }$, donde se plasmaron las reivindicaciones americanas de igualdad de todos los españoles de ambos hemisferios quienes eran «iguales en derechos...quedando a cargo de las Córtes (sic) tratar con oportunidad, y con un particular interés de todo cuanto pueda contribuir a la felicidad de los de ultramar $»^{20}$. Este decreto también abordó el tema de la representación de los americanos en las Cortes encomendándole tratar lo relativo al «número y forma que deba tener para lo sucesivo la representación $»^{21}$.

18. D. S. C. Sesión día 3 de octubre de 1810. Pág. 21.

19. Colección de los Decretos y Órdenes que han expedido las Cortes Generales y Extraordinarias desde su instalación el 24 de setiembre de 1810 hasta igual fecha de 1811. (Imprenta Nacional. Madrid. 1820) [= C.D.O.C.G.] Vol. I. "Decreto 5 de 15 de octubre de 1810. Igualdad de derechos entre los españoles europeos y ultramarinos: olvido de lo ocurrido en las provincias de América que reconozcan la autoridad de las Cortes". [Decreto 5] P. 10. Hay que hacer notar que en dicha edición pone como fecha el 15 de octubre de 1813, cuando debería poner 1810 .

20. Decreto 5 .

21 Decreto 5.

Revista de Ciencias Sociales - Número 63 (2013) - Universidad de Valparáíso - ISSN 0716-7725-Valparaíso, Chile 
El decreto no quedó ahí, pues también reflejó la petición de la amnistía pedida para los pueblos americanos, disponiendo que «ordenan asimismo las Córtes (sic) que desde el momento en que los países de ultramar, en donde se hayan manifestado conmociones, hagan el debido reconocimiento á la legítima autoridad soberana, que se halla establecida en la madre Patria, haya un general olvido de cuanto hubiese ocurrido indebidamente en ellos, dejando sin embargo á salvo el derecho de tercero» ${ }^{22}$.

Como se observa, el decreto liga la extensión del perdón y amnistía al reconocimiento del nuevo orden estatal establecido y la fidelidad a las Cortes reunidas de modo extraordinario. Sólo cumpliendo las condiciones exigidas en el decreto se extenderían las virtudes del perdón estatal a los territorios insurrectos.

Pero el perdón no era total, pues lo ligaba a que los actos no hubieran causado perjuicio alguno a terceros. Con este decreto se vieron cumplidas las expectativas de los diputados americanos y sus exigencias que manifestaron en la sesión de 25 de septiembre de 1810 como condiciones para proceder a la publicación del decreto de instalación de las Cortes, que habían vetado en la sesión del día anterior.

No así los disturbios en América llegaron nuevamente a oídos de las Cortes, hecho que hizo encomendar a la Comisión de Guerra, recientemente creada, hacer un proyecto de decreto para conseguir la tranquilidad en América ${ }^{23}$. Este nuevo periodo insurreccional también culminó en un nuevo decreto de indulto que fue publicado el 30 de noviembre de $1810^{24}$. En él se estableció en el artículo 1, que dicho instrumento normativo se unía al concedido anteriormente, y a su vez reconocía todos los anteriores otorgados por la Corona. El mismo dispuso que el indulto se extendía a todos los «reos de contrabando por extracción é importación de efectos prohibidos, ó venta de los estancados» ${ }^{25}$.

22. Decreto 5 .

23. D. S. C. Sesión día 21 de noviembre de 1810. Pág. 117.

24. "Decreto 14 de 30 de noviembre de 1810. Indulto civil: nueva declaración de olvido general de lo ocurrido en los países de ultramar donde haya habido conmociones”. En C.D.O.C.G. [= Decreto 14]. Vol. I. Pág. 28.

25. Decreto 14.

Facultad de Derecho y Ciencias Sociales - Universidad de Valparaíso - Chile 
Esta extensión se hace también a los reos de penas pecuniarias al fisco ${ }^{26}$, a los reos fugitivos, ausentes y «acusados de contumacia, quienes en el término de seis meses, estando dentro del reino, y de un año, si están fuera» ${ }^{27}$. Sin embargo, hay que hacer notar, que este privilegio se extendía a todos los americanos civiles, incluidos los eclesiásticos, pero no a los de la clase militar ${ }^{28}$.

\subsection{Los problemas nos dividen pero nos une el amor a la "Madre Patria"}

\subsubsection{Disturbios insurreccionales en América}

Tal y como ya se ha expuesto, la situación de América no era muy diferente a la de la España Peninsular, debido a que en muchos partes de los territorios de Ultramar habían surgido insurrecciones. La situación en algunos casos era de guerra, tal y como en España ocurría. La diferencia era que en el caso peninsular la que se había dado en llamar Guerra de la Independencia, el enemigo era el Francés, mientras que en el caso americano el enfrentamiento era contra el poder y los representantes de la Monarquía.

A ello se unía que América tenía muchos otros problemas, pues mientras en la península el asunto más importante era la guerra y la creación de las instituciones que debían gobernar mientras retornaba el Rey ${ }^{29}$, el problema de fondo en América era otro, los excesos de los funcionarios; tema que en gran parte era la causa de las insurrecciones y que por tanto, siempre estaba presente entre sus diputados, haciéndose

\footnotetext{
26. Decreto 14 , artículo 3.

27. Decreto 14 , artículo 4.

28. Decreto 14 , artículo 7.

29. Tema que a su vez dio a lugar a otros quebraderos de cabeza a las Cortes, como la designación de un órgano de regencia, la situación de la rebeldía del Marqués del Palacio, las Cortes, la instauración de un Poder Judicial, o el control del Ejército.
}

Revista de Ciencias Sociales - Número 63 (2013) - Universidad de Valparáíso - ISSN 0716-7725-Valparaíso, Chile 
constar, de hecho, en diversas oportunidades en las Cortes. La actuación abusiva de los funcionarios había sido una constante en América, pero el vacío de poder había dado lugar a un aumento considerable. Nadie iba a interesarse por subsanar esta situación desde la Península, ya que nadie había gobernando el Imperio. Ello motivó levantamientos insurreccionales en diversos lugares, destacando entre ellos el movimiento de Caracas.

Las Cortes Extraordinarias examinados estos acontecimientos, llegaron a la conclusión de que no era posible crear un gobierno conciliador, si se partía desde el rencor. Entendían los diputados, que la única forma de actuar es obviar los conatos insurreccionales, pero no olvidarlos para que no se vuelvan a producir, poniendo los medios posibles para evitarlos en el futuro. Estas medidas pasaban por el previo reconocimiento de Derechos a los indianos y demás españoles de ultramar. Por ello, las Cortes otorgaron el perdón de los agravios cometidos en América en contra de la autoridad y a partir de entonces serán tratados como españoles en igualdad de condiciones que los peninsulares. Pero esta decisión no se adoptó sola, sino que se acompañó de medidas concretas.

A esas alturas los temas de América y la imprenta eran tal vez los más importantes e intensamente tratados en las Cortes, como no podía ser menos. Sin embargo, el tema de la igualdad con Europa fue desplazado por el de los altercados en América que ocuparon durante largo tiempo parte de las discusiones.

El asunto de la igualdad no se volverá a suscitar hasta el 9 de enero del año 1811, pero de un modo muy extenso, pues las opiniones ya son muy encontradas, y máxime cuando ya se estaba decidiendo la representación de las Américas en la comisión de redacción de la Constitución. Las discusiones sobre Ultramar se sucedían siendo los puntos más extensos. La cuestión americana era importante, pues desde el punto de vista de los diputados, eran los propios franceses los que les incitaban a separarse de su patria.

Pero los problemas de dichos territorios no siempre son entendidos y la prueba está en que algunos diputados de la Metrópoli exponían que los asuntos de aquella zona del país, no eran comparables a los problemas que sufría la Península pues no sufrían la ocupación de su territorio.

Facultad de Derecho y Ciencias Sociales - Universidad de Valparaíso - Chile 


\subsubsection{Las soluciones aportadas en las Cortes}

Los diversos problemas surgidos en las Américas dieron gran quebradero de cabeza a los padres Constituyentes, pues su interés no era el de utilizar la fuerza contra los indianos, ni los españoles afincados en América, sino apaciguar de la mejor forma posible las complicaciones, que cada día iban a más. Las medidas conciliadoras adoptadas por las Cortes, entre ellas, el olvido de los agravios de los americanos, la movilización de los oficiales del ejército o la comunicación a los Virreyes de las decisiones que se fueron adoptando como la defensa de los indios, fueron acompañadas de otras disposiciones que se constituyeron en vehículo articulador de la igualdad entre ambos hemisferios.

Además, destacó por su carácter excepcional la extensión del privilegio real de exención de impuestos concedido a los indios del norte, a todos los indios de las Américas ${ }^{30}$ en un momento de falta de ingresos que llevó a la propuesta de la reforma de la Hacienda Real y del comercio para reactivar la exacción pública con la que financiar los gastos que producía la guerra y el país en general. Otras soluciones que se aportaron fueron medidas para el fomento de la agricultura y la industria en América, entre las que destacaron el permiso para fabricar y vender aguardiente en el Virreinato de Méjico, la rebaja de los derechos que se cobraban del pulque, etc. ${ }^{31}$.

30. Es curioso que se arbitre una medida de este tipo, partiendo de que nos encontrábamos en una época de guerra y por tanto de carestía económica y de todo lo necesario para sacar adelante la contienda, conociendo ejemplos de determinados personajes de importancia que costearon las campañas contra los franceses, por ejemplo el caso del Conde de Pinohermoso. Esta medida se plasmó en el Decreto 42 de 13 de marzo de 1811, por el que «se extendía á los Indios y castas de toda las América la exención del tributo concedida á los de Nueva España». El decreto, con un extenso título se reducía a 3 artículos, donde se extendía la «expresada gracia ... a los Indios... de las demás provincias de América». Sobre el particular: "Decreto 42 de 18 de marzo de 1811. se extendía á los Indios y castas de toda las América la exención del tributo concedida á los de Nueva España: se excluye á las castas del repartimiento de tierras concedido á los Indios: se prohíbe a las Justicias el abuso de comerciar con el título de repartimientos” en C.D.O.C.G. Vol. I. Decreto 42. Pág. 90.

31. "Decreto 41 de 12 de marzo de 1811. Varias medidas para fomento de la Pág. 87.

agricultura é industria de América”. en C.D.O.C.G. [= Decreto 41]. Vol. I.

Revista de Ciencias Sociales - Número 63 (2013) - Universidad de Valparáíso - ISSN 0716-7725-Valparaíso, Chile 
A su vez, los Diputados incluían nuevas opciones cada vez que tenían oportunidad. Entre ellas destacaron las realizadas por el Diputado por el Perú, el Sr. Inca, propuesta consistente en un decreto a mandar a los Virreyes y presidentes de las Audiencias de América que con suma escrupulosidad protejan a los indios y cuiden de que no sean molestados ni afligidos en sus personas y propiedades, ni se perjudique en manera alguna a su libertad personal ${ }^{32}$. Sin embargo, a juicio de algunos diputados, como el caso del Sr. Espiga ${ }^{33}$, esta propuesta era pobre, y esta petición merecía un texto articulado que rigiese mejor esta situación ya que a su modo de ver «la encuentro demasiado general». En su opinión, «debía individualizarse por artículos y acompañarle una instrucción (sic) que fuese materia de una discusión» ${ }^{34}$. Las propuestas finalmente se plasmaron en un decreto aprobado con fecha de 5 de enero y con el número 20 de los Dictados por las Cortes Extraordinarias en el que queda patente que ha llamado

«muy particularmente toda la soberana atención de las Cortes generales y extraordinarias los escandalosos abusos que se observan, e innumerables vejaciones que se ejecutan con los Indios primitivos naturales de la América y Asia, y mereciendo á las Cortes aquellos dignos súbditos una singular consideración por todas sus circunstancias» ${ }^{35}$,

exigiendo el decreto que las autoridades correspondientes que

32. D. S. C. Sesión día 16 de Diciembre de 1810, por la noche. Pág. 173.

33. Nos referimos a D. José Espiga y Gadea, diputado por la Junta Superior de Observación y Defensa de Cataluña. Fue Arcediano de Benasque, canónigo de la Catedral de Lérida, auditor del Tribunal de la Rota y Capellán de honor de Carlos IV.

34. D. S. C. Sesión día 16 de Diciembre de 1810, por la noche. Pág. 173.

35. "Decreto 20 de 5 de enero de 1811. Se prohíben las vejaciones hechas hasta aquí á los Indios primitivos” en C.D.O.C.G. [= Decreto 20]. Vol. I. P. 45. Finalmente y pese a lo expuesto por Espiga el Decreto no se articuló, quedando en un único cuerpo declarativo.

Facultad de Derecho y Ciencias Sociales - Universidad de Valparaíso - Chile 
«e dediquen con particular esmero y atencion á cortar de raíz tantos abusos reprobados por la Religion, la sana razon y la justicia, y prohibiendo con todo rigor que... aflija al Indio en su persona ni le ocasione perjuicio el mas leve en su propiedad».

En el caso de contrariar el mandato de las Cortes, estas añaden que merecerá

«todo su desagrado y un severísimo castigo cualquiera infracción que se haga a esta solemne declaración de la voluntad nacional» ${ }^{36}$.

Sin embargo, el tema clave era asegurar una representación igual a la de la Metrópoli.

Finalmente, y con base a los reiterados requerimientos de los diputados americanos, se consiguió una declaración ex profeso de las Cortes, quienes articularon el Decreto 31, de 9 de febrero de 1811. El mismo, reconocía en su primer artículo

«que siendo uno de los principales derechos de todos los pueblos españoles su competente representacion en las Cortes nacionales, la de la parte americana de la Monarquía española en todas las que en adelante se celebren, sea enteramente igual en el modo y forma á la que se establezca en la península, debiéndose fijar en la constitución el arreglo de esta representacion nacional sobre las bases de la perfecta igualdad conforme al dicho decreto de 15 de Octubre último».

Se conseguía así, la declaración solemne de que América tenía en las Cortes el mismo peso que la península, y por tanto, debía tener el mismo número de representantes, asegurándose que este decreto sería traspuesto a la futura Constitución de 1812, exigiendo en la misma un régimen igualitario ${ }^{37}$ para los dos territorios y para los nacionales en ellos residentes.

36. Decreto 20.

37. "Decreto 31, de 9 de febrero de 1811. En que se declaran algunos de los derechos de los Americanos” En: C.D.O.C.G. Vol. 1. Págs. 72-73. Este decreto

Revista de Ciencias Sociales - Número 63 (2013) - Universidad de Valparáíso - ISSN 0716-7725-Valparaíso, Chile 
Esta declaración se consiguió por el empuje de los diputados americanos, quedando a un lado, una declaración similar sobre las colonias de Asia o África, que seguían en inferioridad de condiciones, pese a que posteriormente se incluyan en la propia Constitución de Cádiz ${ }^{38}$.

\subsection{El Reglamento de Provincias de la Monarquía española. La instrumentación político-geográfica del nuevo régimen}

\subsubsection{Los Reglamentos de arreglo de las Provincias. Propuesta de una regulación paralela}

La necesidad de articular todo lo anteriormente visto, reconocer la personalidad propia de América dentro del Imperio y a su vez dar solución a todos los problemas que el vacío de poder había suscitado, dio como resultado la regulación de las provincias por medio de un reglamento que diera una articulación jurídico-política a las distintas regiones de las Españas.

El sistema del Ancien Regime estaba superado y quedaba periclitado ante la nueva situación que se planteaba de reconocimiento de los pueblos de las colonias, cuyo camino hacia un entendimiento con las autoridades culminaría, como es sabido, en su Independencia. Una vez realizada la propuesta por el diputado Antonio Oliveros ${ }^{39}$ para

además del citado pronunciamiento, fue acompañado de otras declaraciones como el derecho de los americanos, tanto españoles como indios, a optar a toda clase de empleos y destinos igual que los españoles europeos, tanto en la corte como en cualquier otro lugar de la monarquía y en las carreras eclesiástica, militar o política, tal y como dispone el artículo 3, o en derecho a sembrar y cultivar o promover la industria manufacturera y las artes en toda su extensión como consigna el art. 2.

38. Constitución Política de la Monarquía Española. Promulgada en Cádiz a 19 de marzo de 1812. [=CEC]. Imprenta Real, Cádiz, 1812, Edición Facsimiliar, Universidad de Cádiz, Cádiz, 2011. Artículo 10. En este artículo se divide América en dos (la norte y la sur) mencionándose cada uno de los territorios. Este mismo tratamiento no lo obtienen el resto de las Colonias, ya que África es asimilada a Canarias, y Asia a las Islas Filipinas por medio de meras menciones generales.

39. Vid. nota al pie 13.

Facultad de Derecho y Ciencias Sociales - Universidad de Valparaíso - Chile 
esta articulación, y elevado el dictamen de la comisión nombrada a los efectos, se comenzó la discusión del reglamento y de las problemáticas que entrañaba el mismo.

Aunque había sido un tema ampliamente tratado en diversas ocasiones, o tocado de soslayo en las discusiones de las Cortes, tal vez, la primera gran reunión a él dedicado fue la sesión del 16 de diciembre de 1810, en la que «casi toda la sesión se reduxo a tratar del proyecto del arreglo de provincias» ${ }^{40}$. En ella se propuso hacer dos reglamentos: uno para Europa (los territorios de la Metrópoli) y otro para América, y una vez aprobado, que dicho reglamento se mande a sus Virreyes. Pero la sesión más que a tratar el problema de América se dedicó a temas económicos, de recaudación, así como a «las ventajas e inconvenientes del actual sistema de rentas» ${ }^{41} \mathrm{o}$ dicho de otra forma «el sistema actual de la Real Hacienda (que) ha sido introducido en España...por la dinastía de los Borbones, y su reforma...» $»^{42}$.

Sin embargo, el asunto de las Provincias volvió a tratarse de nuevo y de forma extensa en la sesión de 20 de diciembre, que se trató como punto VI y último del orden del día, convirtiéndose así en el más extenso de toda la sesión, cuyos puntos anteriores fueron más de trámite que de otra $\operatorname{cosa}^{43}$. En esta sesión se vislumbraron muchos hechos de gran importancia. Entre ellos el fin de la reglamentación, que era articular una solución viable para todas las provincias y regiones de España sin hacer distinción de ningún tipo. Sin embargo, la situación a la hora de tratar el tema de América siempre se espinaba, pues el interés de articular una solución igualitaria para todo el país no se vio factible por algunos diputados. De hecho, esta dicotomía se presenta en la reunión de 20 de

40. Biblioteca Nacional de España. Diario El Conciso. De fecha de 20 de diciembre de 1810. Imprenta de Carreño. Cádiz.

41. D. S. C. Sesión día 16 de diciembre de 1810. P. 171. Alocución del Diputado por Zamora, D. Juan Nicasio Gallego Hernández del Crespo.

42. D. S. C. Sesión día 16 de diciembre de 1810. P. 171. Alocución del Diputado por Asturias D. Agustín de Argüelles y Álvarez González.

43. D. S. C. Sesión día 20 de diciembre de 1810. Pág. 197.

Revista de Ciencias Sociales - Número 63 (2013) - Universidad de Valparáíso - ISSN 0716-7725-Valparaíso, Chile 
diciembre de 1810. En ella, el diputado Argüelles incluso expone a las Cortes que

«será la primera vez que me oponga á que se extienda á América todo lo que se resuelva para la Península. Mi razón principal es porque aquí estamos muy mal y América no está por fortuna en este caso. Aquí se trata de prevenir los daños causados en las provincias invadidas y las que podrán invadirse. Se trata de establecer un régimen general interino...Por lo mismo digo que cualquiera reforma debe ser por ahora independiente de la que se haya de hacer después....» ${ }^{44}$

Ante tal discurso, el diputado Mejía contestó «con sentimiento» que en tal

«supuesto que ese arreglo ha de ser para toda la Península, lo guarde V.M. para sí, porque los males en América son los mismos que aquí, poco más o menos; y si ha de ser solo el arreglo de las Cosas de España, entiendan en ello sólos los Diputados de España» ${ }^{45}$.

Tal contestación suscitó entre los Diputados tensiones, que ponían de relieve que el asunto no era nuevo pues surgió tempranamente, ya en los inicios de las reuniones de Cortes y que el mismo despertaba pasiones entre los representantes peninsulares y los americanos.

La contestación a Mejía fue realizada por Pérez de Castro en la que alude a las claras diferencias entre América y España, exponiendo que lo que Mejía pedía no era posible, que él «no se habría parado a considerar el que pide para América (el reglamento para el arreglo de las provincias), y no habrá visto que hay una absoluta imposibilidad de concederle lo que pide».

44. D. S. C. Sesión día 20 de diciembre de 1810. Pág. 200.

45. D. S. C. Sesión día 20 de diciembre de 1810. Pág. 201.

Facultad de Derecho y Ciencias Sociales - Universidad de Valparaíso - Chile 


\subsubsection{Las Cortes, su discusión y propuesta}

Finalmente, la tesis americana fue la que salió vencedora de la pugna dialéctica sucedida en las Cortes, y se plasmó conforme a la propuesta originaria de un único reglamento para todas las provincias del Imperio Español, en la inteligencia de que todas más o menos tenían problemas similares. Tal vez una de las cuestiones que más importancia tuvieron junto con la imprenta durante los primeros debates de las Cortes fue precisamente el asunto de América y el Reglamento de las Provincias ${ }^{46}$ fue un tema más a tratar dentro del mare magnum americano, aunque tuvo el privilegio de tratarse en una comisión elegida ex profeso, comisión cuya actividad se desarrollaba de forma paralela a la de la Constitución ${ }^{47}$, por lo que no es de extrañar que la tarea desarrollada por aquella influyera en esta a la hora de su redacción ${ }^{48}$.

El resultado fue una norma reglamentaria cuya redacción se extendía a un breve preámbulo, en comparación a los farragosos textos actuales, a un articulado compuesto por 48 preceptos todos ellos de párrafo único, y una breve alocución del mandato de imprimación y cumplimiento $^{49}$.

El fin de dicho reglamento era el de proceder a la articulación jurídico-política del territorio del Reino, consistiendo esta en la creación

46. El reglamento de provincias también es llamado en numerosas ocasiones en los debates de las Cortes Extraordinarias Reglamento para el Arreglo de las Provincias, siendo más utilizada esta denominación que aquella, aunque finalmente fue promulgado con la primera.

47. Ambas comisiones se nombraron en la sesión del 23 de diciembre de 1810 y en el mismo punto del orden del día. Los comisionados para el Reglamento de Provincias fueron los diputados Francisco López Pelegrin, Vicente Traver, José López, Felipe Aner, Manuel Luján, Andrés Esteban, Nicolás Martínez, Antonio Valcárcel y José Morales Gallego. A este respecto ver: D. S. C. Sesión día 23 de diciembre de 1810. Pág. 217.

48. D. S. C. Sesión día 28 de marzo de 1811. P. 772.

49. Nos referimos a la alocución final de las Cortes con la que culmina el Reglamento, en la que manda al Consejo de Regencia que haga lo necesario para su cumplimiento y que sea imprimido para que se conozca y se cumpla.

Revista de Ciencias Sociales - Número 63 (2013) - Universidad de Valparáíso - ISSN 0716-7725-Valparáiso, Chile 
de sistemas de juntas provinciales compuestas por 9 miembros elegidos por el mismo procedimiento que se articulara para la elección de diputados, disponiéndose así para estas elecciones el sistema electoral que diseñaron las Cortes para la elección de Diputados ${ }^{50}$. Las Juntas estaban encabezadas por el Capitán General de la Provincia, por virtud del artículo 3, quien ejercía de Presidente.

El resto de miembros eran 8 y se clasificaban en miembros natos, relacionados en el propio reglamento y miembros elegidos. Estos últimos eran elegidos por sufragio pasivo censitario con el requisito de llevar viviendo en la zona 10 años, tener bienes suficientes, y cuando no sean residentes allí, prescribe el artículo 1 del reglamento que debe por lo menos ser natural de dicho territorio. Este artículo es importante pues en el caso de América pocos residentes naturales de allí podrían optar a ocupar dichos cargos. Casi siempre serían ocupados por los españoles de Europa que fueron allí a acrecentar sus haciendas. La inteligencia de este sufragio censitario viene justificada por la segunda parte del artículo, en la que dice que dichos cargos se desempeñarán sin remuneración ni emolumento alguno ${ }^{51}$. La elección de los miembros de las juntas se producía por tres años, debiendo ser los vocales de las mismas renovados por tercios al principio de cada año ${ }^{52}$. Así mismo, los miembros de la misma poseen fuero propio en las causas criminales pero no en las civiles, debiendo ser denunciados en las Chancillerías o Audiencias territoriales mientras continúen en el desempeño del cargo ${ }^{53}$. Este fuero es una extensión a los miembros de las Juntas del privilegio del que gozan los Diputados de Cortes sobre el mismo particular pero

50. "Reglamento de Provincias", en D. S. C. Sesión de 28 de marzo de 1811 [= R.P.]. Págs. 772-775, y también en C.D.O.C.G. Vol. I. Decreto 43. Págs. 90-103.

51. R. P. Artículo 1 in fine dispone "...en cuanto a la legitimidad de las personas elegidas, quienes deberán servir estos cargos sin sueldo ni gratificación alguna». Esta previsión se mantuvo hasta bien entrado el siglo XIX en la que se vetaba el ingreso a la clase política a los ciudadanos con una renta inferior a lo fijado.

52. R. P. Artículo 5.

53. R. P. Artículo 8.

Facultad de Derecho y Ciencias Sociales - Universidad de Valparaíso - Chile 
que en su caso no se juzgaban en los tribunales citados, sino en un tribunal extraordinario propio de las Cortes y compuesto por Diputados.

Pero finalmente, estas previsiones de dotar a las Provincias o Regiones de un órgano político se vieron contrariadas en el propio reglamento por medio del nombramiento de un Capitán General que no era elegido, por el hecho de que los diputados elegidos desempeñaban a su vez su cargo, con miembros natos o porque esos mismos miembros no eran cargos representativos del pueblo, o por algo mucho más importante, el hecho de que sus competencias se reducían a ejecutar los mandatos de las Cortes, lo cual sustraía cualquier capacidad de decisión a la junta provincial consolidándola en un órgano meramente ejecutor de una política nacional centralizada en Cádiz.

Todo esto, y sobre todo esta última característica, eliminaba toda característica política de las Juntas Provinciales, relegándolas a órganos administrativos $^{54}$ ejecutores de los políticos del Estado que eran las Cortes Generales del Reino o en su caso la Regencia. Esto mismo se concreta en el artículo 13 del reglamento que las reduce a mero

«conducto por donde el Gobierno comunique a los pueblos las órdenes gubernativas y cuantas provinciales estime conveniente dirigirlas para la defensa de la Patria».

El artículo consagra a las juntas provinciales como ejecutoras de lo que el gobierno les encomiende. En el mismo artículo hasta en dos ocasiones lo reproducen diciendo que son «ejecutoras» y que «ejecutarán las juntas cuanto se les prevenga por el Gobierno».

El reglamento en su construcción era bastante generalista, sólo haciendo expresa mención del caso gallego en diversas ocasiones ${ }^{55}$ debido a las especificidades que el territorio del antiguo Reino de Galicia tenía, ya que en el mismo «se hallan más complicadas las jurisdicciones» ${ }^{56}$.

54. PÉREZ JUAN, José Antonio: "El Reglamento Provincial de 1811: La creación de la comisión de Gobierno del Reino de Valencia”. En: Revista de la Facultad de Ciencias Sociales y Jurídicas de Elche. I, Número Especial, Elche, 2009.

55. R. P. Artículos 4, 42, 43 y 44.

56. R. P. Artículo 42.

Revista de Ciencias Sociales - Número 63 (2013) - Universidad de Valparáíso - ISSN 0716-7725-Valparaíso, Chile 
Pero esta excepción no tuvo el carácter de privilegium, sino que en el propio reglamento se habilitaba para adoptar este régimen, a cualquier otra provincia que se encontrase en similar situación que Galicia ${ }^{57}$, siempre que cumpliese las condiciones que en los artículos reguladores de estas circunstancias se diesen.

Este régimen especial se entiende que es aplicable a las provincias con población muy diseminada, o de aldeas y villas de poco censo vecinal. El caso de América era subsumible en este supuesto legislativo, pues existían numerosas poblaciones diseminadas y de reducido vecindario que cumplirían de lleno los requisitos previstos en el reglamento para poder acogerse a este régimen especial que ampliaba la representación de las poblaciones en la Junta Provincial. Estos órganos serían el precedente de las Diputaciones provinciales que posteriormente se trazarían con la reforma de las provincias de Javier de Burgos y su división provincial.

Una previsión que hace el propio reglamento es que se dé el caso en que las Juntas provinciales ya estén constituidas y su número de miembros sea superior al previsto en el propio reglamento. En tal caso, por virtud del artículo $6^{\circ}$, si las Juntas constituidas exceden en el número de componentes de lo previsto en la reglamentación se prevé una medida de derecho transitorio en el referido artículo en el que se reducirá el número al previsto en los artículos 2 y 4, debiendo dimitir los miembros excedentes.

La competencias de las Juntas provinciales están diseminadas por todo el reglamento en el que prevé su labor en materias tan diversas como la contribución a la defensa nacional, el auxilio a los jefes militares por medio de víveres o incluso alistamientos, realizar censos poblaciones "con la diferencia de clases» ${ }^{88}$, fomentar la creación de escuelas, inspección de hospitales militares, entre otras. Otra de las medidas que toma el

57. El artículo 44 del Reglamento de Provincias habilita la extensión del régimen aplicable a Galicia a cualquier otra región cuando dice que «Lo mismo se entenderá para cualquiera otra provincia que se halle en las propias circunstancias, porque haya en ella la reunión de caseríos, cotos, concejos o poblaciones de corto vecindario que en Galicia».

58. R. P. Artículo 21.

Facultad de Derecho y Ciencias Sociales - Universidad de Valparaíso - Chile 
reglamento de importante calado para América es la propuesta de eliminación de los empleos que a su juicio no tengan sentido en el nuevo organigrama, o por el contrario los que habría que crear "procurando que los expedientes vayan bien instruidos para que la determinación sea más pronta y acertada» ${ }^{59}$. Estos expedientes deberán ser enviados a las Cortes y a la Regencia.

El reglamento preveía la posibilidad de que las citadas juntas estuviesen auxiliadas en sus labores por diversas comisiones a nivel local, que tendrían sede en los diversos pueblos o aldeas de su jurisdicción. Estas comisiones tienen encomendadas a su vez diversas competencias que se vislumbran en varios artículos del reglamento ${ }^{60}$. La creación de la comisión se realiza por virtud de un artículo muy posterior, el artículo 33 , es una norma mal situada, por cuanto hasta ese momento ya se ha mencionado en 6 ocasiones la comisión, sin saber qué ha de entenderse por comisión, quién la compone y cuál es la procedencia de sus miembros, debiendo el intérprete hacer una labor de intuición más que de interpretación hasta que descubre la interpretación auténtica de lo que es la Comisión a estos efectos. El mismo está, por tanto, técnicamente mal posicionado, siendo pues un defecto de técnica legislativa.

\section{Conclusión}

Las visiones española y americana de los Diputados en las Cortes Extraordinarias de Cádiz fueron más contrarias de lo que en un principio podía parecer. Las ansias de los americanos de conseguir consolidar un estatuto jurídico similar para sus representados al de los españoles peninsulares. Las reivindicaciones se fueron haciendo cada vez más fuertes hasta que cada vez con más frecuencia consiguen sus objetivos, hasta conseguir un reconocimiento jurídico de derechos a los Españoles de América como les correspondía.

\footnotetext{
59. R. P. Artículo 24.

60. Vid. R. P. Artículos 28, 29 y 33.
}

Revista de Ciencias Sociales - Número 63 (2013) - Universidad de Valparáíso - ISSN 0716-7725-Valparáiso, Chile 


\section{Bibliografía}

ALBORNOZ, Bartolomé Frías de: Arte de los Contratos. Casa de Pedro Huete, Valencia, 1573.

ARTOLA, M.; MORÁN ORTÍ, M.; Las Cortes de Cádiz. Marcial Pons, Madrid, 1991.

CASTRO, A.; Cortes de Cádiz. Complementos de las sesiones verificadas en la Isla de León y en Cádiz. Tomo I. Imprenta de Prudencio

Pérez de Velasco, Madrid, 1913. Edición Facsimiliar. Analecta Editorial. Navarra. 2004.

COMENGE, R.; Antologías de las Cortes de Cádiz. Establecimiento Tipográfico Hijos de J. A. García. Madrid. 1909. Edición Facsimiliar. Analecta Editorial, Navarra, 2004.

CHUST CALERO, M.; Doceañismos, constituciones e independencias: la Constitución de 1812 y América. Fundación Mapfre, Aranjuez, 2006.

CHUST CALERO, M.; América en las Cortes de Cádiz: introducción y selección documental. Fundación Mapfre, Aranjuez, 2010.

GARCÍA GODOY, M. T.; Las Cortes de Cádiz y América: el primer vocabulario liberal español y mejicano (1810-1814). Diputación de

Sevilla, Sevilla, 1998.

GARCÍA LOZANO, L. M.; "Artifex Legis en el Liber Iudiciorum. Una antigua teoría con total vigencia”. En: Estudios de Derecho y

Ciencia Política. Universidad de Salamanca. Salamanca. En prensa.

LABRA y MARTÍNEZ, R. M. de; Los presidentes americanos de las Cortes de Cádiz. Imprenta Manuel Álvarez, Cádiz, 1912.

PÉREZ GARZÓN, J. S.; Las Cortes de Cádiz: Constitución del estado y creación de la nación. Contenido en: Lecturas sobre 1812.

Ayuntamiento de Cádiz, Cádiz, 2007.

PÉREZ JUAN, J. A.; "El Reglamento Provincial de 1811: La creación de la comisión de Gobierno del Reino de Valencia". En: Revista de la Facultad de Ciencias Sociales y Jurídicas de Elche. I. Número Especial, Elche, 2009.

SUÁREZ, F.; Actas de la Comisión de Constitución (1811-1813).Ediciones del Instituto de Estudios Políticos, Madrid, 1976.

Facultad de Derecho y Ciencias Sociales - Universidad de Valparaíso - Chile 


\section{Fuentes}

Colección de los Decretos y Órdenes que han expedido las Cortes Generales y Extraordinarias desde su instalación el 24 de setiembre de 1810 hasta igual fecha de 1811. T. I, Imprenta Nacional, Madrid, 1820.

Constitución Política de la Monarquía Española. Promulgada en Cádiz a 19 de marzo de 1812. Imprenta Real, Cádiz, 1812, Edición Facsimiliar, Universidad de Cádiz, Cádiz. 2011.

Diario de sesiones de las Cortes Generales y Extraordinarias: dieron principio el 24 de setiembre de 1810 y terminaron el 20 de setiembre de 1813.Vol. I, Imprenta de J.A. García, Madrid, 1870-1874.

Diario de las Discusiones y actas de las Cortes. Imprenta Nacional, Cádiz, 1813.

El Conciso. Archivo Biblioteca Nacional Española. De fecha de 20 de diciembre de 1810, Imprenta de Carreño, Cádiz.

Reglamento de Provincias. Aprobado por el Decreto 43 de 1811. 